\title{
Factors Contributing to Industrial Conflicts within Higher Education Institutions in Lesotho: A Case of the National University of Lesotho
}

\author{
Mamoeletsi Limakatso Mojalefa \\ Department of Business and Management Development \\ National University of Lesotho, Lesotho \\ E-mail: mjlmojalefa@gmail.com
}

Received: January 4, 2021 Accepted: January 30, $2021 \quad$ Published: June 2, 2021

doi:10.5296/ber.v11i2.18550 URL: https://doi.org/10.5296/ber.v11i2.18550

\begin{abstract}
Incidences of industrial actions, which have frequently paralyzed learning at most of the educational institutions, are frequent in Lesotho. Despite the safeguards for collective bargaining in Lesotho, the incidences of industrial actions at higher institutions of learning in Lesotho are still common. The study was conducted to investigate the factors which contribute to industrial conflict at the National University of Lesotho. In order to gain a deeper understanding of the participants' unionism experiences, semi-structured interviews were used to collect data. This study reveals that lack of transparency, inconsistent application of policies, lack of communication, lack of motivation, poor salaries, bias as well as poor working conditions are some of the factors that cause strikes at the institutions of higher learning in Lesotho.
\end{abstract}

Keywords: Industrial conflict, Higher education, Conflict, Trade union

\section{Introduction}

Globally, and in particular in Lesotho, every year at least one or more sectors will embark on an industrial action. In recent years, education sector has been plagued by industrial action. In Lesotho, the recent, prolonged industrial action was embarked upon by primary and secondary schools teachers during 2019(Government of Lesotho official communication, 2019 Internet source; Lesotho Times, 2019 Internet Source). During industrial action the employees end up resorting to violent and destructive engagement, ending in property looting and destruction if their plight is not responded to. On the other hand employer or management engage in retaliatory tactics such as suspending employees engaged in industrial 
action, and invoking a policy of "no-work-no-pay" (Cohen and Matee 2014). On the other hand employees will hold the employer hostage by not performing a strategically significant activity such as administering and processing examinations. Such negative spill overs affect quality of education negatively, and where possible should be avoided.

\section{Literature Review}

Strikes at the work place are mainly caused by employee and employer disagreements and conflicts over a number of things (Kibris2015). Globally, internal and external conflicts are on the increase in all sectors including education. Conflicts at the workplace arise because of a number of issues such as interpersonal tensions, ethnic differences, vested interests on policies and norms, inefficient and ineffective administrative processes and leadership styles. Lencioni (2005) lists different types of settings where conflicts occur such as environmental issues, relationship issues and individual issues occur. Environmental issues relate to the atmosphere in which the conflict is taking place; for instance, office politics, and personal attitudes as well as institutional. Relationship obstacles include all issues between the staff of an organization and prior unresolved legacies or events between different groupings in the organization. Lencioni (2005) adds that individual obstacles are specific to each person in the conflict. In the situation at hand, the context fits that of environmental obstacles since it involves institutional arrangement. Lencioni (2005) suggests that when a conflict arises, the parties concerned should alter the resolution model to address the issue.

Lack of clear procedures at an academic institution can create conflict between lecturers and students (Hardy 1997) as well as between teachers and administrators. Policy makers and management can use a conflict as a scapegoat for poor performance and other failings in an organization such as poor academic performance (Thrupp and Lupton 2006).

Conflicts at higher education institutions occur in different contexts. For example, in the Philippines, conflicts at education institutions are triggered by religious and cultural differences (Bernardo and Baranovich 2014). In Yemen, studies report that violations of the regulations related to the first appointment of lecturers, the absence of research ethics code as well as disregarding of staff's suggestions are the most important causes (Muthanna 2013, 2015; Muthanna and Karaman 2014; Muthanna 2016).

Teacher strikes in West Virginia and Oklahoma are caused by agitation for salary increases, which are among the lowest in the nation, and have been stagnant for years. Kentucky teachers' salaries rank 27 th out of 51 among the U.S.A. states which still $\$ 13,000$ below the $\$ 65,383$ average are for all American teachers. It's not surprising that teachers in those states have rejected the calls for patience (in some cases, even calls from their union leaders) and decided to demand action from their state legislature (Thrupp and Lupton 2006). These strikes have been to be caused by:

- The refusal of state legislatures to maintain financial support for public schools, and the tendency of most states to slash support for public education in order to lower or hold down taxes at both the state and local levels

- The political movement to blame teachers and teacher unions for weaknesses in public 
education, attacking teacher tenure, tying teachers' evaluations to student test scores and clearing out protections for collective bargaining, rather than acknowledging that the cooperation of the teachers and their unions is essential to any improvements in public education

In South Africa, rivalry between unions in the same sectors, the problem of historical poverty, competition for jobs with migrant workers, agitation for wage increases as well as the mismatch between wage offers and demands are the main causes of the numerous strikes (Murwirapachena 2014). In Kenya, issues such as oppression of women, as seen within the context of unequal gendered power relations, is a common cause of employee discontent at the work place and rank high in union agenda (Kaloki 2017). Specific women related issues such as sexual harassments rarely feature in union agenda during negotiations or collective bargaining. Moreover, there are no suitable platforms where women can form synergy to tackle their specific problems or to network. With the increasing number of educated women entering the workforce, there is a consistent paradigm shift, with more women showing interest and performing well in trade union leadership roles. Factors that lead to strikes at the workplace are similar in many countries. However, the consistency of reporting differs from country to country. For example, in Kenya, and South Africa, union activities are well documented while in some countries such as Lesotho, there is paucity of reporting.

In Lesotho, the causes of strikes at higher institutions of learning have not been properly documented although the cases of strikes have a long history. For example, in 1958 workers at the Morija Printing Works went on strike in response to expulsions of workers at the printing press that members considered unfair and discriminatory, and political factors are believed to have led to the 1961 strike (Mohlakola, 1986). Mohlakola (1986) further argues that some political leaders have tended to use unions as stepping stones to political success. Makoa (1988) singles out the failure by government to review labor relations laws to the standards of the International Labor Organization's as anti-union stance. Such laws, the author notes, include the Essential Services Arbitration Act of 1975, which outlawed strikes at industries providing essential services and disbanded the pre-independence trade unions. According to the Ministry does not detract them from what is embodied in the ILO Conventions" (Makoa, 1988). Makoa (1988) argues that the constraints imposed by these laws outweigh the advantages that they offer. The main problems facing trade unionists in Lesotho, and which are some of the major causes of strikes in the country, are the stalling or refusal by employers to negotiate. Makoa (1988) further argues that legal remedies for these problems are either not available or too costly to apply.

\section{Methodology}

\subsection{Research Design}

The study adopted qualitative approach. Different techniques of data collection, such as interviews and documentary research, which were used in this study ensures trustworthiness of the research. The entire interview process was recorded and archived to protect the data from loss, damage or manipulation and, hence, available for reference should doubts emerge of the authenticity of the field research. 


\subsection{Data Analysis}

In order to gain a deeper understanding of the participants' unionism experiences, semi-structured interviews were used to collect data. According to Bevan (2014), when interviews are selected as the method of data collection, the researcher is free to structure the interview in a manner that enables thorough investigation. Therefore the present researcher used semi-structured interviews to maintain consistency across the interviews, as each interview begins with a similar set of questions. When semi-structured interviews are used to collect data, predetermined questions and special topics are covered during the interview. There is more flexibility when conducting semi-structured interviews, since other topics could emerge in order to provide more information that may be of importance to the researcher (Gideon, 2012; Myers, 2013).

\section{Results}

The findings of the study revealed the following eight factors which contribute to industrial conflict at the National University of Lesotho.

\subsection{Lack of Transparency}

Els, Erasmus and Viviers (2014) describe business transparency as an essential condition for a free and open exchange, whereby the rules and reasons behind regulatory measures are fair and clear to all participants. Meanwhile, another source defines transparency as "the full, accurate and timely disclosure of information. It is obvious that doing business in a non-transparent manner causes conflict between the employees and management.

The literature on lack of transparency revealed that if employees perceive an organization, top management or heads of departments to be highly transparent, the overall return of the organization, individual and group success are significant. It is more likely to build a sense of stability, spirit of volunteerism, team work, commitment, solidarity and integrity. However, Ashana (2013) mentions that lack of corporate governance principles such as transparency, integrity, openness trustworthiness, honesty and accountability has led to the collapse of many business ventures in Africa. Most entrepreneurs violate corporate governance principles. There is no transparency, integrity or openness in the way they conducted their businesses. Corruption is the order of the day. There is lack of responsibility and accountability in the way business is conducted. Most microfinance institutions award loans, not according to the laid procedures but according to whom they know. This has led to the collapse of many businesses.

Conflict is a central element in labor relations and therefore needs to be well managed. This is reiterated by Ehlers (2007) who states that the differing values, needs, expectations, attitudes, objectives, affiliations, interests and approaches of employers and employees constitute the basic cause of conflict in labor relations. As such managing conflict is supposed to be the most important focus areas of managers, employee representatives and employees.

\subsection{Inconsistence Application of Policies}

Both the LUTARU and NAWU members indicated that inconsistency in implementing 
policies at NUL causes frustration among the employees. The participants stated that this has been the problem at NUL for quite a long time and it has not been addressed. Sometimes, some employees normally resort to legal action where they sue NUL for inconsistency and most of the time NUL loses cases in the courts of law.

Mayhew (2019) indicates that consistent application and enforcement of workplace policies is the responsibility of human resources, department supervisors and managers. The consequences of applying workplace policies inconsistently can jeopardize business success. Mayhew (2019) further points out that companies that pick and choose which policies to implement normally fail. Such companies do not only fail, but they also expose themselves to potential liability for employee complaints about unfair treatment. When employees raise their complaints about inconsistent application of policies, this can lead to conflict.

It is a good thing for companies to have well-written employment policies, but it is only half the battle. If they are not applied, they are like tools rusting away. Worse, if they are applied inconsistently among employees, they can become tools of destruction. Consequently, that is where conflict comes in.

\subsection{Bias}

Bias leaves dissatisfaction among the teaching staff and causes conflict among staff. This segregation in terms of benefits has also extended to some managerial positions, further worsening the conflicts as some managers are remunerated more than even the teaching staff. This has sown division among the university staff members.

Unconscious bias is prejudices that we are unaware of. They are "mental shortcuts based on social norms and stereotypes" (Guynn, 2015). Bias can be based on skin color, gender, age, height, weight, introversion versus extroversion, marital and parental status, disability status (for example, the use of a wheelchair or a cane), foreign accents, where someone went to college and other factors (Wilkie, 2014). If you can name it, there is probably an unconscious bias for it. These biases cause us to make decisions in favor of one group to the detriment of others (Ross, 2008) and naturally creep into the workplace. Scores of studies document how unconscious bias affects workplace decisions

\subsection{Non-separation of Cadre}

The Findings indicate that there is no separation of cadre at NUL between teaching (Academic) staff and nonteaching (administrative) staff. This is shown by lack of categorization of jobs which created discomfort and dissatisfaction among staff.

Responses show that NUL is failing the teaching staff when it comes to rewards. This is because all teaching staff has argued that NUL rewards do not do justice to them. They feel that support staff are paid more even though in terms of workload they do more work than the support staff.

Subject to Section 10 and in particular Sub-Section 10 (2) (f) of the National University of Lesotho Act and Statute 24, the Academic Staff of the University shall consist of the Professors, Readers, Senior Lecturers, Senior Research Fellows, Lecturers, Research Fellows, 
Assistant Lecturers and such members of the Library and the Administrative Organization of the University as are appointed by the University on academic terms of service.

Ehlers (2007) states that job evaluation entails the reviewing of a job, and determining the relative value of a job by assigning a numerical value to the job. This numerical value is then coupled with a corresponding remuneration package that has been determined by research and/or negotiation. However, if people are not rewarded for the job, this can be a potential factor for conflict.

\subsection{Low Salaries}

In addition, other participants who were LUTARU indicated that NUL rewarded teaching and non-teaching staff the same way which they felt was not supposed to be the case because they have different contracts which require different qualifications and experiences. It is apparent that most teaching staff are not happy with low salaries that NUL provides. The academic staff as well as the non-academic have complained about poor remuneration standards.

Low salaries are a contributing factor to strikes and protests that take place in organizations. It is the most visible of a number of factors contributing to industrial conflict. Even at NUL, most of the time when there is unrest, one of the issues which always arises is low salaries. Though a relatively low pay has been a historical, well-known feature of the teaching profession, most of the public does not know that many lecturers at higher education institutions are feeling a pinch in their remunerations more extremely.

\subsection{Poor Working Conditions}

The GOL abides by the guidelines of the International Labor Organization (ILO) and subsequently adopted policies that ensure the protection of many labor rights in Lesotho. For the purpose of this study, the focus was on the right to protection, safety and health. This implies that employees may render their services in safe working conditions, with safe machinery and equipment and that their lives and health will not be exposed in any other way to unnecessary dangers. The study revealed that poor working conditions contributed to conflict in that some employees were frustrated due to poor working conditions and created unhappiness among them. Hence conflict between employees and management.

The participants indicated that NUL cannot produce the expected marketable products as expected. This is because the environment does not allow the lecturers and facilitators to do their jobs perfectly. For example, a student from the faculty of Science is expected to be competent and practical but if he was guided under poor conditions, such a student cannot be competent. At the same time, when such students fail, the University Senate expects j expects an explanation from the lecturers about the high failure rate or poor performance. During the interview, it was discovered that such remarks from the Senate committee upset the concerned lecturers and they later confront their deans for failing to protect them yet they know that for the whole academic year that the inadequacy of resources issues were not addressed, hence the students' poor performance. Where there is a confrontation among the employees, it is a sign of conflict. 
This means, therefore, that when the employees are not working in a conducive environment, their performance tends to decline; ultimately, this leads to the University being unable to achieve its goals and objectives. When NUL is failing to achieve its goals, stakeholders criticize it over the media. This causes conflicts because management expects the employees to deliver their services effectively and efficiently despite the inadequacies in the faculties. The University management knows that it has contributed to the decline in the students' performance.

\subsection{Lack of Motivation}

The findings revealed that NUL treats its employees as though they are all equal in terms of capabilities and qualifications and this situation demoralizes teaching and research. There are times when tension reigned among the employees.

Lack of motivation is regarded as a potential cause of conflict. An unmotivated employee either quits on the job or is about to quit for real while happy employees stay with the company and, more importantly, deliver work of a high standard. They contribute actively to both the workplace culture and the organization's intellectual capital.

According to Maslow's hierarchy of needs, human needs fall into five progressive levels: physiological, safety, social and love, esteem and self-actualization. As needs at one level is gratified, they lose their motivational strength and the next level of needs is activated with a corresponding motivational influence (Ehlers, 2007). When the employees are not recognized in terms of qualifications, as indicated by one participant, it is evident that there will be conflict among the employees.

\subsection{Lack of Communication}

The responses showed that NUL does not communicate its policies to the employees and this, according to the findings, leads to conflict not only between the employees and managers but even among employees themselves. Poor communication is one of the main causes of conflict between employees and employers in the workplace. This can result from a difference in communication styles or a failure to effectively communicate the policies and procedures. Failing to communicate in the workplace may cause the employees to make incorrect assumptions and raise workplace gossip.

Wille De Fruyt and Feys (2013) mentions that when communication lines between the employees and their bosses are not running smoothly, the workplace becomes a challenging environment. It is vital for communication to begin from upper management and filter through to each employee so that people feel safe, comfortable, motivated and clear in their work goals. Poor communication is the easiest way for a company to lose sight of what it can achieve. When the company is in the state of poor communication, the possibility of conflict arising is very high. As indicated in the first paragraph, employees may make incorrect assumptions because not all the procedures would have been clear to them. When they fail to adhere to some of the policies, then they are likely to face disciplinary actions. This means trust relationship between the employees and employers is broken and, automatically, conflict comes in. 
Having work rules does not mean much unless the employees know that the rules exist and understand them clearly. In addition, effective communication of such policies or principles is important not only because it helps the employees to understand the rules but also because documented communication of those rules makes it easier to enforce them, if necessary.

Good communication is of the utmost importance in maintaining satisfactory levels of employee performance. Management is responsible for telling the employees precisely what is expected of them and for ensuring that all standards, rules and regulations are clearly communicated (Wanich et al, 2015). They define communication as the glue that binds various elements, coordinates activities, allows people to work together and produce satisfactory results.

\section{Conclusions}

The findings from the field survey show that the factors which contribute to conflict at NUL include: lack of transparency, inconsistent policies, bias, non-separation of Cadre, poor working conditions as well as lack of communication of policies, procedures and rules. From the findings, it is evident that the long term impacts include strikes, employee turnover and erosion of quality.

Respondents indicated that poor working conditions at NUL do not only affect the employees but they also affect students. One element of poor working condition surveyed was the low salaries that the respondents noted was a cause of conflict at NUL. When the lecturers approach the management for the solution to poor working environment issues, they are promised that things will be fine but to no avail. In the literature search, it is indicated that low salaries are the main cause of strikes at the workplace not only in developing countries but also in advanced countries. . Even in the neighboring South Africa several issues relating to poor conditions of work such as inequality, the use of migrant workers and poor working conditions are noted as the main causes of strikes

According to the findings, strikes at the university are also caused by poor communication among staff at NUL on policies, procedures and rules. This includes communication between management and staff as was indicated by some union members of NAWU and LUTARU who said that the policies and rules are sometimes applied on employees without prior consultations. According to the above response, it is evident that lack of motivation is one of the factors which contributes to conflict. The respondents also indicated that lack of motivation is one of the factors which contribute to strikes at the National university of Lesotho.

Strikes have long lasting impact on both the staff and the institution itself, which in turn can result in policy makers and administrators treating conflict as a good excuse for low-quality education and/or low achievements. The findings of the field research indicate that strikes, which are common at NUL, have significant consequences which include low staff morale, poor student performance, nepotism, high staff turnover and lack of monitoring. The response showed that there are employees who are discouraged to the extent that they no longer even go to work to campus for their duties. Lack of clear procedures at an academic institution can 
create conflict between the lecturers and students (Hardy 1997) and teachers and administrators.

One of the prominent factors which has contributed to conflict at NUL is the inconsistent application of policies across the organization by managers. The above responses illustrate that implementing policies inconsistently is the major contributing factor to industrial conflict at NUL. In the literature review section, it is shown that lack of clear procedures at academic institutions often creates conflicts between lecturers and students and teachers and administrators. Makoa (1988: 3) argues the main problems facing trade unionists in Lesotho and which are some of the major causes of strikes in the country, is the stalling or refusal by employers to negotiate. He further argues that the legal remedies for these problems are either not available or too costly to apply.

The non-separation of cadres was also noted as a major concern for the employees. It is similar to bias unequal pay and inconsistency in applying the laws and regulations. The teaching staff have argued that NUL does not do justice to them when they are rewarded. They feel that support staff are paid more even though they have a heavier load than the support staff. The findings show that some employees entice management to do favors for them. One of the main causes of strikes at NUL is unequal pay for men and women. Lack of transparency was also noted to be a common cause of conflict at NUL between the employees and the employer. This is an area that has not been looked at I previous studies and is new knowledge that will help in the development of information in this field.

When the employees are no longer motivated, they become angry and go on strike or they simply resign. Those who stay behind compromise quality in their service delivery and ultimately they go on strike. These repercussions are both by staff and students as well as the institutions alike, as illustrated by the study findings.

The response revealed that not all the employees can stand the frustration of inadequate resources which hinder their service delivery. This means that some employees decide to resign and join other organizations. Another issue which was raised is that of NUL failing to attract quality staff. Here the emphasis was on professors who do not join NUL because of low salaries.

\section{References}

Bernardo, M. A. C., \& Baranovich, D. (2014). Higher Education in the Heart of Armed Conflict: The Pivotal Role of Student Affairs. International Journal of Educational Development, 35, 78-85. https://doi.org/10.1016/j.ijedudev.2012.08.007

Cohen, T., \& Matee, L. (2014). Public Servants' Right to Strike in Lesotho, Botswana and South Africa - A Comparative Study. PELJ/PER V., 17(4).

https://doi.org/10.4314/pelj.v17i4.12

Elhers, L. (2007). Labour Relations Systems, Procedures and Practice. Pretoria. EAMS Publishing.

Els, G., Erasmus, P., \& Viviers, S. (2014). Corporate Finance: A South African Perspective 
(2nd ed.). Oxford University Press, South Africa.

Gideon, L. (2012). The Art of Question Phrasing. In Handbook of Survey Methodology for the Social Sciences. Springer New York. pp. 91-107.

https://doi.org/10.1007/978-1-4614-3876-2_7

Hardy, C. (1997). Sources of Conflict during the School Experience of Pre-Service Physical Education Teachers. European Physical Education Review, 3(2), 116-128.

https://doi.org/10.1177/1356336X9700300203

Kaloki, T. (2017). Women Labour Empowerment through Trade Unions in Kenya. [Online] Available: https://www.fes-connect.org/people/women-labour-empowerment-through-trade-uni ons-in-kenya

Kibris, A. (2015). The Conflict Trap Revisited: Civil Conflict and Educational Achievement. Journal of Conflict Resolution, 59(4), 645-670. https://doi.org/10.1177/0022002713516845

Lencioni, P. (2005). Overcoming the Five Dysfunctions of a Team: A Field Guide for Leaders, Managers, and Facilitators. JuaayBeaa Inc. ASIN: B004C7KWA0

Makoa, F. K. (1988). Collective Bargaining and the Application of International Labour Organisation's Conventions in Lesotho. A Discussion Paper presented at an ILO/LFTU Workshop held at Maseru Cabanas Hotel, Maseru.

Myers, M. D. (2013). Qualitative Research in Business \& Management (2nd ed.). Sage Publications, London.

Mohlakola, M. (1986). Early Trade Unions in Lesotho (1950-1966). Dissertation in the Faculty of Humanities: National University of Lesotho.

Murwirapachena, G. (2014). Exploring the Incidents of Strikes in Post-Apartheid South Africa. International Business and Economics Research Journal, 13(3), 553-560.

https://doi.org/10.19030/iber.v13i3.8592

Muthanna, A. (2013). A Tragic Educational Experience: Academic Injustice in Higher Education Institutions in Yemen. Policy Futures in Education, 11(5), 532-537.

https://doi.org/10.2304/pfie.2013.11.5.532

Muthanna, A. (2015). Quality Education Improvement: Yemen and the Problem of the 'Brain Drain'. Policy Futures in Education, 13(1), 141-148.

https://doi.org/10.1177/1478210314566734

Muthanna, A. (2016). Plagiarism: A Shared Responsibility of All, Current Situation, and Future Actions in Yemen. Accountability in Research, 23(5), 280-287.

https://doi.org/10.1080/08989621.2016.1154463

Muthanna, A., \& Karaman, A. C. (2014). Higher Education Challenges in Yemen: Discourses on English Teacher Education. International Journal of Educational Development, 37. https://doi.org/10.1016/j.ijedudev.2014.02.002 
Thrupp, M., \& Lupton, R. (2006). Taking school contexts more seriously: the social justice challenge. British Journal of Educational Studies, 54(3), 308-328.

https://doi.org/10.1111/j.1467-8527.2006.00348.x

Wille, B., De Fruyt, F., \& Feys, M. (2013). Big five traits and intrinsic success in the new career era: A 15 year longitudinal study on employability and work-family conflict. Applied Psychology: An International Review, 62, 124-156.

https://doi.org/10.1111/j.1464-0597.2012.00516.x

\section{Copyright Disclaimer}

Copyright for this article is retained by the author(s), with first publication rights granted to the journal.

This is an open-access article distributed under the terms and conditions of the Creative Commons Attribution license (http://creativecommons.org/licenses/by/4.0/). 